\title{
Nursing diagnoses of impaired memory and chronic confusion for older adults: diagnostic content validation
}

Diagnósticos de enfermagem memória prejudicada e confusão crônica para idosos: validação de conteúdo diagnóstico

Diagnósticos de enfermería memoria deteriorada y confusión crónica en adultos mayores: validación del contenido diagnóstico

Priscilla Alfradique de Souza' ORCID: 0000-0002-4625-7552

Kay Coalson Avant" ORCID: 0000-0002-2390-2985

Andrea E. Berndt" ORCID: 0000-0002-4658-5230

'Universidade Federal do Estado do Rio de Janeiro. Rio de Janeiro, Rio de Janeiro, Brasil. "University of Texas Health Science Center at San Antonio, San Antonio, Texas, United States of America.

How to cite this article: Souza PA, Avant KC, Berndt AE. Nursing diagnoses of impaired memory and chronic confusion for older adults: Diagnostic content validation.

Rev Bras Enferm. 2021;74(Suppl 2):e20200370. doi: http://dx.doi.org/10.1590/0034-7167-2020-0370

Corresponding author: Priscilla Alfradique de Souza E-mail: priscillalfradique@gmail.com

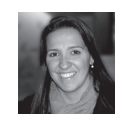

EDITOR CHEFE: Antonio José De Almeida Filho EDITOR ASSOCIADO: Marcos Brandão

Submission: 06-06-2020 Approval: 15-10-2020

\begin{abstract}
Objective: To validate the defining characteristics of the nursing diagnoses, impaired memory and chronic confusion for older adults, by testing diagnostic concept definitions among expert nurses. Methods: We used a Diagnostic content validation using an online survey of expert clinical nurses. Results: 195 expert nurses performed the diagnostic validations. Findings provided validity of impaired memory with 11 major defining characteristics and chronic confusion, with 11 major and one minor defining characteristics. In both diagnoses, content validity index was 0.85 . Factor analysis provided four and five supported factors for impaired memory and chronic confusion, respectively. Conclusion: The study provided evidence of validity of the two diagnoses and made them clearer. Using these updated nursing diagnoses, nurses have the potential to improve accuracy and quality of care for elderly patients, contributing to more accurate nursing gerontological care.

Descriptors: Nursing Diagnosis; Memory Disorders; Confusion; Geriatric Nursing; Validation Study.
\end{abstract}

\section{RESUMO}

Objetivo: Validar as características definidoras dos diagnósticos de enfermagem memória prejudicada e confusão crônica para idosos, testando as definições dos diagnósticos entre enfermeiros especialistas. Método: Validação de conteúdo diagnóstico utilizando um questionário online para enfermeiros clínicos especialistas. Resultados: 195 enfermeiras especialistas realizaram as validações diagnósticas. Os resultados demonstraram a validade de memória prejudicada com 11 características definidoras principais, e confusão crônica com 11 características definidoras principais e uma secundária. Em ambos os diagnósticos, o índice de validade de conteúdo foi de 0,85. A análise fatorial forneceu quatro para memória prejudicada e cinco fatores para confusão crônica. Conclusão: $O$ estudo forneceu evidências de validade dos dois diagnósticos, tornando-os mais claros. Por meio do uso desses diagnósticos de enfermagem atualizados, os enfermeiros podem melhorar a precisão e a qualidade do atendimento a pacientes idosos, contribuindo para um cuidado gerontológico de enfermagem mais preciso.

Descritores: Diagnóstico de Enfermagem; Transtornos da Memória; Confusão; Enfermagem Geriátrica; Estudo de Validação.

\section{RESUMEN}

Objetivo: Validar las características que definen los diagnósticos de enfermería memoria deteriorada y confusión crónica en adultos mayores, testeando las definiciones de los diagnósticos entre enfermeros especialistas. Método: Se trata de una validación del contenido diagnóstico realizado mediante un cuestionario en línea para enfermeros clínicos especialistas. Resultados: Las validaciones de diagnóstico las llevaron a cabo 195 enfermeras especialistas. Los resultados demostraron la validez del deterioro de la memoria con 11 características principales definidoras y la confusión crónica, con 11 principales definidoras y una secundaria. En ambos diagnósticos, la tasa de validez del contenido fue de 0,85 . El análisis factorial proporcionó cuatro factores para el deterioro de la memoria y cinco para la confusión crónica. Conclusión: El estudio trajo evidencias de la validez de los dos diagnósticos y los dejó más claros. Al valerse de estos diagnósticos actualizados, los enfermeros pueden mejorar la precisión y la calidad de la atención de los pacientes adultos mayores y contribuir aún más con el cuidado gerontológico de enfermería.

Descriptores: Diagnóstico de Enfermería; Trastornos de la Memoria; Confusión; Enfermería Geriátrica; Estudio de Validación. 


\section{INTRODUCTION}

As a result of increased life expectancy, the population of older adults has grown exponentially, leading to extended human longevity ${ }^{(1)}$. The older adult population aged 65 years or older, will grow from an estimated 703 million in 2019 to over 1.5 billion by $2050^{(2)}$. Concomitant to this increase in older adults is often an increase in cognitive impairment. Concerns about cognitive decline, such as loss of memory, have even begun extending into mid-life.

Although memory deficit may be attributed to normal aging, specifically in areas related to attention and speed of processing ${ }^{(3-4)}$, cognitive decline may be caused by pathological causes. Understanding potential causes of cognitive decline is important, as they interfere with the independence of people, and may cause depression, loss of autonomy, early retirement, increased health care costs, and increased mortality rates ${ }^{(5-7)}$.

Recently, the nursing diagnoses (ND) of impaired memory (IM, Code \#00131) and chronic confusion (CC, Code \#00129) have been increasingly observed among older adults. The terms IM and CC were currently defined in the NANDA International (NANDA-I) Taxonomy II in Domain 5, Class $4^{(8)}$. The ND of IM was prevalent in $61,61 \%$ of hospitalized elders on a specialized unit of a general Brazilian hospital ${ }^{(9)}$. In addition, a prospective study of 123 older adults living in a long-term care institution found IM in $31 \%$ of participants ${ }^{(10)}$, while the ND CC was identified in $90 \%$ of older adults living in a long-term care institution ${ }^{(11)}$.

Researchers noted similarities between CC and other concepts, such as dementia ${ }^{(12-14)}$, and acute confusion ${ }^{(15)}$. However, this was more evident when $\mathrm{CC}$ was compared to $\mathrm{IM}^{(16)}$. Thus, there was an overlap between the defining attributes of IM and CC, leading to misunderstanding.

This misunderstanding has led to confusion among nurses as to how to choose which diagnosis is appropriate for each patient ${ }^{(16)}$ and has significantly influenced the choice of interventions. Clear diagnostic concepts are needed to support nurses who care for elders daily. When diagnostic criteria overlap or are not clearly differentiated, accuracy can be compromised and significantly affects the care provided to the person for whom the diagnosis applies. IM and CC are two such diagnoses. While IM requires assistance related to memory problems and strategies to prevent or postpone progression, $\mathrm{CC}$ requires more intense nursing care as a reason of already installed older adults' dependency. Therefore, there was a need to clearly differentiate these two diagnoses, particularly for gerontological nurses who care for older adults on a daily basis.

\section{OBJECTIVE}

To validate the defining characteristics of the nursing diagnoses, impaired memory and chronic confusion for older adults, by testing diagnostic concept definitions among expert nurses.

\section{METHODS}

\section{Ethical aspects}

This study was approved by the Research Ethics Committee at The University of Texas Health Science Center at San Antonio.
The invitation letter and the proposed consent form were included as part of the survey. The researcher did not collect any identifiable information, and all findings were aggregated. All responses were encrypted and stored on a password-protected Survey Monkey server.

\section{Design, period and place of study}

The present study proposed a diagnostic content validation (DCV) of two nursing diagnoses, adapted from the method proposed by Fehring ${ }^{(17)}$ using an online survey. The DCV followed the guidelines of reporting reliability and agreement studies (GRRAS). This study is a report of the third phase of a larger study developed to determine how the key concepts of impaired memory and chronic confusion were observed in clinical practice by nurse experts ${ }^{(18-19)}$. The setting for this study was Texas, USA, and data collection occurred during the period of April to May, 2015.

\section{Population or sample; criteria of inclusion and exclusion}

Nurses from the NANDA-I association membership database and networking site members of the American Psychiatric Nurses Association were invited to participate using a web-based invitation letter. Nurses attending the Western Institute of Nursing (WIN) Conference were also invited to participate by provision of an invitation letter at the poster site of WIN. Given the analysis to be developed in relation to the number of defining characteristics (DC) of this study, the recommended sample size of 115 participants or more was calculated based on a power analysis with an alpha level of 0.05 , effect size of 0.30 , and a power $(\beta)$ of $0.80^{(20)}$.

Expert nurses with a master's degree in nursing (MSN) and specialized knowledge in the field of the diagnoses studied were the desired participants ${ }^{(17)}$. Given the difficulties of meeting these criteria in web-based and validation studies, the length of time nurses worked in the clinical setting was used as an indicator of specialized knowledge in the field ${ }^{(21-22)}$.

Therefore, the inclusion criteria were nurses with at least a master's degree and/or a minimum of five years of practical experience in the related field of the ND; those who scored a minimum of 5 points on the adapted Fehring criteria $^{(17)}$; and those who were willing to respond to the instrument in English. The criteria adapted from Fehring was: length of time a nurse had worked in the clinical setting as an indicator of experience. Thus, at least five years of nursing experience in the pertinent field was also considered a minimum requirement for participation in the study. The exclusion criterion was not to complete the entire survey.

\section{Study protocol}

Data were collected using a DCV survey of the ND of IM and CC. The survey was an electronic version of an expert panel review instrument, previously validated. The link to access the survey was embedded in the invitation letter. The survey was semi-structured and consisted of three sections.

The first section was the information sheet, which provided an introduction, the purpose of the study, information about 
informed consent and anonymity, and instructions to complete the survey. The second section included demographic items regarding professional experience, and history of research related to the ND, and/or specific studies/practical experiences with the diagnoses, to determine if the participant met the requirements for expert characterization. The third section included the survey, consisting of definitions, DC, and operational definitions for both ND. Operational definitions for both ND were validated in previous stage of the study, during expert panel review. Two new DC were also included and validated in the expert panel review. For IM, "Preserved capacity to perform daily activities independently", and for CC, "Inability to perform at least one daily activity". These ND were based on the most recent NANDA-I nursing diagnosis edition at the time ${ }^{(8)}$.

Participants were asked to review each DC of each diagnosis in terms of clarity, relevance, and importance. The criteria has as meanings: 1)Clarity refers to the extent to which the DC is well written, distinct, and easily understood; 2)Relevance refers to the extent to which the DC is connected to and directly related to the presented diagnosis; 3)Importance refers to the extent to which the DC is essential to the presented diagnosis and can discriminate between the two diagnoses ${ }^{(23)}$.

\section{Analysis of results and statistics}

Data were analyzed using IBM-SPSS ${ }^{\circ}$ software, version 20.0. All analyses were performed with a level of significance of $5 \%{ }^{(24)}$. The analysis was developed in two stages. First, descriptive statistics were generated. Next, the DCV, definitions, DC, and operational definitions were assessed. The DCV process was used to evaluate the degree of clarity, relevance, and importance of the DC for each diagnosis, using a 5-point Likert scale, to indicate the degree experts agreed or disagreed using the following scores "not at all; slightly; somewhat; moderately; and very." Data analysis responses were replaced by the following values: not at all $=1$; slightly $=2$; somewhat $=3$; moderately $=4$; and very $=5$. To gauge the validity of the evaluations made by the nurses, the content validity index $(\mathrm{CVI})$ was calculated. To calculate CVI, the sum of the values attributed to each DC was divided by the number of experts. The weighted average of the scores was calculated for each DC, which represents the CVI of each DC, presenting values from 0 to $1^{(19,25)}$.

The DC with a CVI of 0.80 or higher were considered critical evidence, which means they were major characteristics of the ND of IM and CC. Those with a CVI between 0.60 and 0.79 were classified as secondary evidence, also defined as minor characteristics. Those with CVI of 0.59 or lower were considered not relevant to the diagnoses and should be rejected ${ }^{(17,19,22)}$.

Chi-square $\left(X^{2}\right)$ analyses were performed to assess sample equivalence between nurse participants with incomplete surveys (group that did not finish answering the entire survey and were excluded from the study) and complete surveys (group that finished answering the entire survey and were the final sample of the study) and. This analysis was performed to make sure both groups (participants with complete and incomplete surveys) were equivalent. In the second stage of the analysis of this study, an exploratory factor analysis (EFA) was performed to assess construct validity and distinguish the ND according to relevance and importance ${ }^{(23)}$.

Factorability was measured using KMO (Kaiser-Meyer-Olkin) and Bartlett's Test of Sphericity. These measures examine the extent to which items meet the assumptions of univariate and multivariate normality. The KMO measure of sampling adequacy (MSA) tests for univariate normality and should be a minimum of $0.70^{(23-24)}$. Values between 0.70 and 0.80 are considered respectable and values between 0.80 and 0.90 are considered very good $^{(24-25)}$.

Bartlett's Test of Sphericity tests for multivariate normality and the value should be significant (lower than 0.05$)^{(24)}$. IM and CC data met the criteria for univariate and multivariate normality $(p<.001)$. Therefore, separate EFA analyses were performed for IM and CC. EFA of the DC was performed using Varimax and Promax rotations ${ }^{(19,23,25)}$ to determine the best interpretation of the solutions. Internal consistency was determined after interpretation of the EFA findings, using Cronbach's alpha as an estimate of reliability.

\section{RESULTS}

\section{Demographics}

Two hundred seventy nurses agreed to participate in the survey. From this total, 195 (72.2\%) met the inclusion criteria and completed the entire survey. The majority were female (94\%), white, non-Hispanic (89\%), worked in the United States (95\%), spoke English as their primary language (94\%), had Masters' degrees (63\%), and worked over 20 years as a Registered Nurse (75\%). The nurses worked in the areas correlated to the diagnoses: adult, geriatric, and psychiatric mental health.

\section{Sample Equivalence}

In relation to the adapted Fehring inclusion criteria ${ }^{(17)}$ for each expert nurse, the mean score was 11.2 points $(S D=2.2$, Minimum $=6$ and Maximum = 17), with 45.9\% (90) of nurse participants achieving 11 points. When comparing nurses with incomplete surveys to nurses with complete surveys (group that finished answering the entire survey and were the final sample of the study), the groups had similar characteristics, confirming homogeneity of the recruited population. Specifically, for those who completed the surveys, $99 \%(n=194)$ had more than 5 years of experience, and $84.2 \%(n=165)$ earned a MSN. In addition, almost $50 \%(n=97)$ had published papers in relevant areas, and $95 \%(n=185)$ worked in areas related to this study.

\section{Diagnostic Content Validation}

The first content validation was done for the nursing diagnosis of IM. This diagnosis was defined as "Persistent inability to remember or recall bits of information or skills". All 11 DC of IM were validated and considered major DC by the expert nurses who participated in the study, scoring between 0.87 and 0.89 on content validity indices (CVI) (Table 1). The indices were scored according to the ratings given on the three criteria and in the 
total score by the nurses, who analysed each DC of this ND. When the individual criteria were analyzed, two DC were rated below 0.80 on the importance criterion. They were:"Persistent inability to learn a new skill" and "persistent inability to retain a new skill," scored as 0.79 , equally. For the total and mean scores, none of the $11 \mathrm{DC}$ had a value below 0.81 .

The second content validation was done for the ND of CC. This diagnosis was defined, as "Irreversible, progressive, insidious, and long-term alteration of intellect, behavior and personality, manifested by impairment in cognitive functions (memory, speech, language, decision making, and executive function), and dependency in execution of daily activities". These indices were scored as were those for IM. For the ND CC, none of the DC had scores below 0.59, with no suggestion for exclusion (Table 2). The DC, "no changes on level of alertness," was considered a minor DC (secondary evidence), with a .73 score. All the remaining 11 DC were considered major DC (critical evidence), scoring between .80 and .91 .

When the individual criteria were analyzed, one DC was rated below 0.80 on the importance criterion. It was: "Adequate alertness to surroundings," with a 0.79 score. For the total and mean scores, 11 DC had scores equal or above .80 , and one DC had a score of 0.73 . Therefore, all the DC of CC evaluated were validated by the nurses.

Interestingly, in both ND, the DC evaluated by nurses had similar scores. The DC had strong CVI ratings of .84 and .86 for relevance, clarity, and importance. The total CVI in both ND was 0.85 , thus strongly supporting the validity of the two diagnoses.

\section{Factor Analysis and Reliability}

Separate EFA analyses were performed for IM and CC. For $\mathrm{IM}$, the overall KMO was 0.84. and Bartlett's was statistically significant, $X^{2}(231)=5061.84, p<0.001$. Therefore, the IM data met the criteria for univariate and multivariate normality. When evaluated for relevance and importance, most of the items for IM were scored between $4.47(S D=0.86)$ and $4.05(S D=1.05)$.

A Promax rotation of the scores for the DC of IM, resulted in four components (Table 3). No items loaded on more than one factor. The total proportion of variance explained was $75.21 \%$. All factors were strongly supported, presenting positive values between .96 and .72 .

For CC, the overall KMO for CC was 0.81 and Bartlett's was statistically significant, $X^{2}(276)=5273.97, p<0.001$. Thus, the CC data met the criteria for univariate and multivariate normality. When evaluated for relevance and importance, most items for CC scored between $4.60(S D=0.76)$ and $4.03(S D=1.26)$. Three items were scored slightly lower, "adequate alertness to surroundings, importance," scored 3.97 $(S D=1.26)$, "no changes on level of alertness", relevance, scored 3.65 $(\mathrm{SD}=1.26)$, and importance, scored $3.66(\mathrm{SD}=1.23)$.

A Promax rotation for the scores of the DC of CC identified 5 factors (Table 4). "Long term cognitive impairment loaded on both Factor 3 and Factor 5 but was retained in Factor 3 as the fit was better. The total variance and the cumulative proportion explained $75.15 \%$ of the variance. The factors were strongly supported and presented positive values between 0.95 and 0.52 . Both IM and CC, presented Cronbach's a of 0.95 indicating excellent reliability. No items were recommended for deletion that could enhance reliability.

Table 1 - Content Validity Index for the Defining Characteristics of Impaired Memory, Texas, USA

\begin{tabular}{|c|c|c|c|c|}
\hline Defining Characteristics of Impaired Memory & R-CVI & C-CVI & $\mathbf{I - C V I}$ & T-CVI \\
\hline Persistent forgetfulness & 0.89 & 0.85 & 0.88 & 0.87 \\
\hline Consistently forgets to perform a behavior at the scheduled time & 0.87 & 0.85 & 0.86 & 0.86 \\
\hline Persistent inability to recall if a behavior was performed & 0.89 & 0.86 & 0.88 & 0.88 \\
\hline Persistent inability to recall familiar names, words, or objects & 0.89 & 0.84 & 0.87 & 0.87 \\
\hline Persistent inability to recall factual information or events & 0.88 & 0.84 & 0.87 & 0.86 \\
\hline Persistent inability to perform a previously learned skill & 0.89 & 0.88 & 0.89 & 0.89 \\
\hline Persistent inability to learn a new skill & 0.82 & 0.83 & 0.79 & 0.81 \\
\hline Persistent inability to learn new information & 0.83 & 0.85 & 0.82 & 0.83 \\
\hline Persistent inability to retain a new skill & 0.81 & 0.83 & 0.79 & 0.81 \\
\hline Persistent inability to retain new information & 0.86 & 0.86 & 0.83 & 0.85 \\
\hline Preserved capacity to perform daily activities independently* & 0.86 & 0.87 & 0.85 & 0.86 \\
\hline MEAN SCORE & 0.86 & 0.86 & 0.84 & 0.85 \\
\hline
\end{tabular}

Note: $C=$ Clarity, $C V I=$ Content Validity Index, I = Importance, $R=$ Relevance, $T=$ Total score (Mean of Clarity, Importance, and Relevance), ${ }^{*}=$ Activities of Daily Living \& Instrumental Activities of Daily Living. (CVI represents the proportion of raters in agreement about a given rating. CVI of 0.80 or greater is considered critical evidence.).

Table 2 - Content Validity Index for the Defining Characteristics of Chronic Confusion, Texas, USA

\begin{tabular}{|c|c|c|c|c|}
\hline Defining Characteristics of Chronic Confusion & R-CVI & C-CVI & I-CVI & T-CVI \\
\hline Progressive impairment in cognitive functioning & 0.92 & 0.88 & 0.92 & 0.91 \\
\hline Insidious and irreversible onset in cognitive impairment & 0.90 & 0.85 & 0.90 & 0.88 \\
\hline Long-term cognitive impairment & 0.90 & 0.86 & 0.90 & 0.89 \\
\hline Alteration in short-term memory & 0.86 & 0.86 & 0.86 & 0.86 \\
\hline Alteration in long-term memory & 0.89 & 0.86 & 0.87 & 0.87 \\
\hline Alteration in at least one cognitive function other than memory & 0.87 & 0.84 & 0.86 & 0.86 \\
\hline Alteration in personality & 0.84 & 0.80 & 0.83 & 0.82 \\
\hline Alteration in behavior & 0.84 & 0.83 & 0.82 & 0.83 \\
\hline Alteration in social functioning & 0.86 & 0.86 & 0.84 & 0.85 \\
\hline Adequate alertness to surroundings & 0.81 & 0.80 & 0.79 & 0.80 \\
\hline No changes on level of alertness & 0.73 & 0.73 & 0.73 & 0.73 \\
\hline Inability to perform at least one daily activity* & 0.88 & 0.89 & 0.88 & 0.88 \\
\hline MEAN SCORE & 0.86 & 0.84 & 0.86 & 0.85 \\
\hline
\end{tabular}

Note: $C=$ Clarity, $C V I=$ Content Validity Index, EPR = Expert Panel Review, I = Importance, $R=$ Relevance, T=Total score (Mean of Clarity, Importance, and Relevance), ${ }^{\prime}=$ Activities of Daily Living \& Instrumental Activities of Daily Living. (CVI represents the proportion of raters in agreement about a given rating. CVI of 0.80 or greater is considered critical evidence.). 
Table 3 - Promax Rotation Results for Relevance and Importance of Impaired Memory, Texas, USA

\begin{tabular}{|c|c|c|c|c|c|}
\hline \multirow{2}{*}{ Defining Characteristics } & \multicolumn{4}{|c|}{ Factor Loadings } & \multirow{2}{*}{ C } \\
\hline & 1 & 2 & 3 & 4 & \\
\hline Persistent forgetfulness: $\mathrm{R}$ & & & 0.75 & & 0.64 \\
\hline Persistent forgetfulness: I & & & 0.74 & & 0.63 \\
\hline Consistently forgets to perform a behavior at the scheduled time: $\mathrm{R}$ & & & 0.92 & & 0.81 \\
\hline Consistently forgets to perform a behavior at the scheduled time: I & & & 0.84 & & 0.76 \\
\hline Persistent inability to recall if a behavior was performed: $\mathrm{R}$ & & 0.52 & & & 0.72 \\
\hline Persistent inability to recall if a behavior was performed: I & & 0.50 & & & 0.72 \\
\hline Persistent inability to recall familiar names, words, or objects: $\mathrm{R}$ & & 0.84 & & & 0.71 \\
\hline Persistent inability to recall familiar names, words, or objects: I & & 0.92 & & & 0.74 \\
\hline Persistent inability to recall factual information or events: $\mathrm{R}$ & & 0.59 & & & 0.65 \\
\hline Persistent inability to recall factual information or events: I & & 0.72 & & & 0.64 \\
\hline Persistent inability to perform a previously learned skill: $\mathrm{R}$ & & 0.77 & & & 0.71 \\
\hline Persistent inability to perform a previously learned skill: I & & 0.79 & & & 0.73 \\
\hline Persistent inability to learn a new skill: $\mathrm{R}$ & 0.84 & & & & 0.76 \\
\hline Persistent inability to learn a new skill: I & 0.86 & & & & 0.79 \\
\hline Persistent inability to learn new information: $\mathrm{R}$ & 0.85 & & & & 0.80 \\
\hline Persistent inability to learn new information: I & 0.86 & & & & 0.80 \\
\hline Persistent inability to retain a new skill: $\mathrm{R}$ & 0.90 & & & & 0.81 \\
\hline Persistent inability to retain a new skill: I & 0.89 & & & & 0.77 \\
\hline Persistent inability to retain new information: $\mathrm{R}$ & 0.84 & & & & 0.80 \\
\hline Persistent inability to retain new information: I & 0.81 & & & & 0.77 \\
\hline Preserved capacity to perform daily activities independently: $R$ & & & & 0.93 & 0.87 \\
\hline Preserved capacity to perform daily activities independently: I & & & & 0.96 & 0.93 \\
\hline Rotation Sums of Squared Loadings in Pattern Matrix & 9.38 & 9.03 & 7.28 & 4.92 & \\
\hline
\end{tabular}

Table 4 - Promax Rotation for Relevance and Importance of Chronic Confusion, Texas, USA

\begin{tabular}{|c|c|c|c|c|c|c|}
\hline \multirow{2}{*}{ Defining Characteristics } & \multicolumn{5}{|c|}{ Factor Loadings } & \multirow[t]{2}{*}{ C } \\
\hline & 1 & 2 & 3 & 4 & 5 & \\
\hline Progressive impairment in cognitive functioning: $\mathrm{R}$ & & 0.84 & & & & 0.72 \\
\hline Progressive impairment in cognitive functioning: I & & 0.85 & & & & 0.71 \\
\hline Insidious and irreversible onset in cognitive impairment: $R$ & & 0.91 & & & & 0.77 \\
\hline Insidious and irreversible onset in cognitive impairment: I & & 0.95 & & & & 0.78 \\
\hline Long-term cognitive impairment: $\mathrm{R}$ & & & 0.42 & & 0.43 & 0.71 \\
\hline Long-term cognitive impairment: I & & & 0.47 & & 0.53 & 0.72 \\
\hline Alteration in short-term memory: $\mathrm{C}$ & & & 0.74 & & & 0.67 \\
\hline Alteration in short-term memory: I & & & 0.84 & & & 0.75 \\
\hline Alteration in long-term memory: $\mathrm{R}$ & & & 0.80 & & & 0.77 \\
\hline Alteration in long-term memory: I & & & 0.81 & & & 0.70 \\
\hline Alteration in at least one CF other than memory: $\mathrm{R}$ & & 0.59 & & & & 0.64 \\
\hline Alteration in at least one CF other than memory: I & & 0.52 & & & & 0.61 \\
\hline Alteration in personality: $\mathrm{R}$ & 0.79 & & & & & 0.81 \\
\hline Alteration in personality: I & 0.77 & & & & & 0.78 \\
\hline Alteration in behavior: $\mathrm{R}$ & 0.78 & & & & & 0.77 \\
\hline Alteration in behavior: I & 0.82 & & & & & 0.80 \\
\hline Alteration in social functioning: $\mathrm{R}$ & 0.75 & & & & & 0.80 \\
\hline Alteration in social functioning: I & 0.71 & & & & & 0.78 \\
\hline Adequate alertness to surroundings: $\mathrm{R}$ & & & & 0.76 & & 0.76 \\
\hline Adequate alertness to surroundings: I & & & & 0.76 & & 0.78 \\
\hline No changes on level of alertness: $\mathrm{R}$ & & & & 0.88 & & 0.80 \\
\hline No changes on level of alertness: I & & & & 0.92 & & 0.81 \\
\hline Inability to perform at least one daily activity: $\mathrm{R}$ & & & & & 0.89 & 0.81 \\
\hline Inability to perform at least one daily activity: I & & & & & 0.96 & 0.83 \\
\hline Rotation Sums of Squared Loadings in Pattern Matrix & 7.84 & 7.18 & 7.32 & 6.43 & 6.26 & \\
\hline
\end{tabular}

Note: $C=$ Communalities.; $C F=$ Cognitive Function; Factor Loadings: $1=$ Social and individual characteristics; $2=$ Longstanding impairment of cognitive functions; $3=$ Memory impairment; $4=$ Alert ness and attention; $5=$ Dependent daily activities; $I=$ Importance; $N=195 ; R=$ Relevance.

\section{DISCUSSION}

In this study, results supported the validation of IM and CC for older adults by the expert nurses. Both diagnoses were validated via content analysis with the same CVI values (0.85), suggesting participants understood the DC of IM and CC as relevant, clear, and important. In relation to representativeness of the DC of both diagnoses, evaluated by the experts, the results indicated that of $23 \mathrm{DC}, 22$ met the proposed diagnostic content validation as critical evidences.
When evaluated according to the criteria, the scores of relevance and importance in CC were slightly higher (0.86 and 0.86 ). IM scored 0.86 for relevance and 0.84 for importance. The EFA brought new information for ND validation, strengthening the DC and identifying underlying dimensions Psychometric analysis has been applied frequently with success to provide evidence in different taxonomies ${ }^{(26)}$, supporting associations between variables, in this case, the DC. These associations evidenced in factor loadings can help guide determination of health responses to help identify the specificities of each ND(15). 
Previous studies found, in differential diagnostic validation of the IM and CC DC and related factors, that the DC of the two diagnoses were commingled, making the concepts difficult to distinguish ${ }^{(16)}$. The current study was the first study that evaluated IM and CC simultaneously for diagnostic content validation. Almost 200 (72.2\%) nurses completed the DCV survey, which exceeded the minimum sample size for the required analysis and was a significant size for an online survey ${ }^{(21)}$.

For IM, nine DC adapted from the official list of NANDA- $I^{(8)}$, had scores above or equal to 0.80 and were validated as major DC. The performed adaptation was made based on the expert panel review, according to suggestion to include some terms, such as "persistent" and "consistent" in the DC. They were: "Persistent forgetfulness"; "Consistently forgets to perform an activity at the scheduled time"; "Persistent inability to recall if a behavior was performed"; Persistent inability to recall familiar names, words, or objects"; "Persistent inability to recall factual information or events"; "Persistent inability to perform a previously learned skill”; Persistent inability to learn a new skill"; "Persistent inability to learn new information"; Persistent inability to retain new information". Those findings were similar to previous studies ${ }^{(9-10)}$, in which learning and retaining information were identified as important memory skills for screening IM.

In addition, "persistent inability to retain a new skill" and "preserved capacity to perform daily activities, activities of daily living (ADL) and instrumental activities of daily living (IADL) independently, two DC that were not part of the NANDA-I list ${ }^{(8)}$, were also validated as critical evidence for IM. In older adults without other cognitive impairment associated, only the capacity to memorize is impaired. The abilty to develop IADL and ADL, remains the same, as in the IM. This might be related to the fact that the person builds skills through time and knows already how to perform these abilities and apply other complementary strategies to keep performing activities independently ${ }^{(27-28)}$.

The processes of retaining and recalling information or skills are critical parts of the memory, that might be related to several chronic diseases other than dementia ${ }^{(9,28-29)}$ and directly interfere with the ability of elders to learn and keep new information and competencies $^{(3)}$. This inability may pose the necesssity to start taking notes and increasing focus in attention to maintain activities independently ${ }^{(30)}$.Thus, the impairment of these abilities constitutes critical attributes for IM and further justifies the relevance of these DC.

The ability of "preserved capacity to perform daily activities (IADL \& ADL) independently" was validated as one of the highest scores (0.86) for IM. Although it was not observed in previous diagnosis validation studies ${ }^{(9-10)}$, this has been considered one of the main characteristics to differentiate IM from CC. This preserved capacity occurs because the elder, in this case, is able to apply different cognitive strategies that will help to perform the required activity ${ }^{(28,30)}$. While literature usually indicates DC are constituted by problems evidenced ${ }^{(8)}$, "preserved capacity to perform daily activities (IADL \& ADL) independently" was not a problem; rather it was a "normal" pattern. In contrast, this content validation found this DC crucial for a diagnosis determination of IM.

For CC, 11 DC had scores above or equal 0.80 and were validated as major Only one DC, "no changes on level of alertness," was validated as a minor DC (0.73). This lower score may be related to difficulty in differentiating the ND CC and acute confusion, as the latter may be superimposed in patients with $\mathrm{CC}^{(31)}$. Therefore, the change in level of alertness throughout the day is often observed in patients with acute confusion, also known as"sundown effect"(15,31-32). Conversely, this rapid change is not observed in patients with CC, as the pattern of changes persists from days to weeks ${ }^{(28,31-32)}$.

A content validity study of CC was conducted with 251 Slovak and Czech nurses ${ }^{(14)}$, containing DC and concepts from the MiniMental State Examination (MMSE). Only one DC, "disorientation (in time and space)", from the MMSE was validated as a major DC. Six DC ("progressive impairment in cognitive functioning, "longterm cognitive impairment, "alteration in short-term memory, "alteration in long-term memory," "alteration in personality," and "alteration in social functioning") were validated as minor $\mathrm{DC}^{(14)}$ and as major DC in the current study, suggesting suitability for CC.

Although many cases of CC present maintenance of alertness to surroundings, patients with Lewy Body dementia may exhibit a pronounced variation in alertness and attention ${ }^{(28,33)}$, explaining the score (0.80) for "adequate alertness to surroundings." Individuals with cognitive decline usually express progression of impairment through time ${ }^{(7,33-34)}$. However, continuous cognitive decline is not certain (i.e., IM progresses to $C$, is diagnosed with CC, or starts with IM and never progresses to $C C)^{(28,34)}$.

Although IM causes problems in other areas, the major issue is related to memory. Usually, an ineffective health response for a short period of time, considered reversible, reflecting in the memory and/ or in other cognitive abilities, is acute confusion ${ }^{(15)}$. However, if there are permanent difficulties (after treatment of reversible causes), the diagnosis is $I \mathrm{M}^{(9-27)}$. Finally, if the problems reach other cognitive areas, added to demonstration of dependency, the diagnosis is $\mathrm{CC}^{(30,33-34)}$. These clarifications were submited to NANDA-I and approved to inclusion in the 11 edition, specially regarding the topic related to dependency and development of daily activities ${ }^{(35)}$.

The use of instruments that allow identification of human responses related to the neurcognitive abilities may support nurses to implement a more effective nursing care plan for older adults with neurocognitive disorders. With the progression of cognitive decline in older adults, the complexity of care progresses proportionally, increasing dependence and vulnerability Therefore, these aspects need to be considered by those involved: family, caregivers, health care professionals and gerontological nurses to provide integral care ${ }^{(29)}$.

\section{Study limitations}

Content validation has usually low evidence levels, since there is no clinical practice data, only experts' perspective. That may be considered a limitation. However, it is very important for diagnostic validation. Generalizability was supported by the participation of nurses from different locations, who shared similar clinical areas (e.g., American and European nurses). However, other global areas (e.g. Asian and African nurses) were not included, which might be considered a limitation of this study.

\section{Contributions to the fields of Nursing, Health or Public Policy}

The study showed the relevance of developing a diagnostic content validation. This method is recommended for other ND 
studies in which two or more diagnoses have overlapping or redundant characteristics. These updated ND may contribute to more accurate nursing care. The accurate identification of ND significantly affects the choice of the correct intervention, generating thus, more assertive and resolutive nursing care. The results can help to provide academic discussions about ND related to cognitive disabilities, gerontological care, and mental health. These ND should be included in teaching plans within educational settings. Findings may support better communication between nurses, families, and individuals with cognitive impairment, promoting early detection and improvements in the quality of care.

\section{CONCLUSION}

The content validation of the ND of IM and CC was achieved. Expert nurses validated the DC for both diagnoses, confirming the representativeness of the DC and their application for older adults. From a total of 23 DC, 22 were validated as critical evidence.
The validation suggests nurses understood both diagnoses as relevant, clear, and important to support gerontological care.

As a consequence, this study may support a clear delineation of more accurate DC based on the perspective of a large group of expert nurses. The major differences evidenced were: 1) IM interferes in most cases with deficits in memory and does not cause dependency; while 2) CC interferes with several areas of cognition (including memory) and causes dependency. With this evidence, nurses taking care of older adults may be more supported to adequately identify the human responses that will support their decision making in diagnoses related to the cognitive domain. Future studies considering other nursing components, different age groups, as well as clinical diagnosis validation should be considered.

\section{FUNDING / ACKNOWLEDGMENT}

NANDA International Foundation grant award, and the William F. Castella professorship in aging grant award.

\section{REFERENCES}

1. Pignolo RJ. Exceptional human longevity. Mayo Clin Proceed. 2019;94(1):110-24. doi: 10.1016/j.mayocp.2018.10.005

2. United Nations. World Population Ageing 2019. New York: United Nations; 2020. 36 p.

3. Craik FIM. Remembering: an activity of mind and brain. Annual Review of Psychology. 2020;71:1-24. doi: 10.1146/annurev-psych-010419-051027

4. Bezdicek O, Červenková M, Georgi H, Schmand B, Hladká A, Rulseh A, et al. Long-term cognitive trajectory and activities of daily living in healthy aging. Clin Neuropsychol. 2020:1-17. doi: 10.1080/13854046.2020.1745895

5. Wittenberg R, Knapp M, Hu B, Comas-Herrera A, King D, Rehill A, et al. The costs of dementia in England. Int J Geriatr Psychiatr. 2019;34(7):1095103. doi: 10.1002/gps.5113

6. Carrasco MP, Montenegro-Peña M, López-Higes R, Estrada E, Crespo PD, Rubio MC, et al. Subjective Memory Complaints in healthy older adults: fewer complaints associated with depression and perceived health, more complaints also associated with lower memory performance. Arch Gerontol Geriatr. 2017;70:28-37. doi: 10.1016/j.archger.2016.12.007

7. Sandoval JJ, Turra CM, Loschi RH. Adjusted mortality rates attributable to Alzheimer's disease dementia, Brazil, 2009-2013. Cad Saúde Pública 2019;35(6):e00091918. doi: 10.1590/0102-311x00091918

8. Herdman, TH, Kamitsuru S, editors. NANDA International Nursing Diagnosis: Definitions \& Classification, 2015-2017. Oxford: Wiley-Blackwell; 2014. $512 \mathrm{p}$.

9. Ferreira GL, Lopes MVO, Montoril MH, Diniz CM, Santana RF. Clinical validation of the nursing diagnosis of impaired memory in patients with a stroke. Japan J Nurs Sci. 2019;16(2):136-44. doi: 10.1111/jjns.12220

10. Montoril MH, Lopes MVO, Santana RF, Sousa VEC, Carvalho PMO, Diniz CM, et al. Clinical validation of the NANDA-I diagnosis of impaired memory in elderly patients. App Nurs Res. 2016;30:32-7. doi: 10.1016/j.apnr.2015.08.005

11. Silva TG, Souza PA, Santana RF. Adequacy of nursing language to the practice with elderly residents in a long-term psychiatric institution: cross mapping. Rev Pesqui: Cuid Fundam. 2015;7(4):3467-78. doi: 10.9789/2175-5361.rpcfo.v7.4963

12. Deutchki IM. What's causing my older patient's cognitive decline? J Fam Pract [Internet]. 2017 [cited 2020 Sep 9];66(11):670-6. Available from: https://cdn.mdedge.com/files/s3fs-public/Document/November-2017/JFP06611670_0.PDF

13. Louredo DS, Sá SPC, Camacho ACLF, Câmara VD, Louzada ABD, Rodrigues IB. The relationship between the nursing diagnosis and cognition tests performed on elderlies with Alzheimer's disease. Rev Pesqui: Cuid Fundam. 2014;6(1):271-81. doi: 10.9789/2175-5361.2014v6n1p271

14. Tomagová M, Bóriková I. Validation of the nursing diagnosis chronic confusion in Slovak and Czech nursing practices. Profese Online. 2012;1:1-6. doi: 10.5507/pol.2012.006

15. Sampaio FMC, Sequeira CAC. Nurses' knowledge and practice in cases of acute and chronic confusion: a questionnaire survey. Perspect Psychiatr Care. 2015;51(2):98-105. doi: 10.1111/ppc.12069

16. Souza PA, Santana RF, Cassiano KM. Differential validation of nursing diagnoses of impaired memory and chronic confusion. Rev Enferm UFPE. 2015;9(7):9078-85. doi: 10.5205/1981-8963-v9i7a10700p9078-9085-2015 
17. Fehring R. The Fehring Model. In: Carrol-Johnson R, Paquete M, editors. Classification of nursing diagnoses: proceedings of the tenth conference of North American Nursing Diagnosis Association. Philadelphia: Lippincott; 1994:55-62.

18. Lynn MR. Determination and quantification of content validity. Nurs Res. 1986;35(6):382-5. doi: 10.1097/00006199-198611000-00017

19. Polit DF, Beck CT. Fundamentos da pesquisa em enfermagem: avaliação de evidências para a prática da enfermagem. 9th ed. Porto Alegre: Artmed; 2019. $456 \mathrm{p}$.

20. Cohen, J. Statistical power analysis for the behavioral sciences. 2nd ed. Hillsdale: Lawrence Erlbaum Associates Inc; 1988.567 p.

21. Cavalcante AMRZ, Lopes CT, Swanson E, Moorhead SA, Bachion MM, Barros ALBL. Validation of definitions of the indicators for Nursing Outcomes Classification outcomes: self-management cardiac disease. Acta Paul Enferm. 2020;33(e-APE20180265). doi:10.37689/acta-ape/2020ao0265

22. Lopes MVO, Silva VM, Araujo TL. Methods for establishing the accuracy of clinical indicators in predicting nursing diagnoses. Int J Nursing Knowledge. 2012;23(3):134-9. doi: 10.1111/j.2047-3095.2012.01213.x

23. Pasquali L. Psicometria: teoria dos testes na psicologia e na educação. 5th ed. Petrópolis: Vozes, 2018. 392 p.

24. Field A. Discovering statistics using SPSS. 5th ed. Thousand Oaks: Sage; 2017. 856 p.

25. De Vellis, RF. Scale development: theory and applications. 4th ed. Thousand Oaks: Sage; 2016.

26. Sampaio FMC, Araújo OSSL, Sequeira CAC, Canut MTL, Martins T. Evaluation of the Psychometric Properties of NOC Outcomes "Anxiety Level" and "Anxiety Self-Control" in a Portuguese Outpatient Sample. Int J Nursing Knowledge. 2018;29(3):184-91 doi: 10.1111/2047-3095.12169

27. Dixe MA, Braúna M, Camacho T, Couto F, Apóstolo J. Mild cognitive impairment in older adults: analysis of some factors. Dement Neuropsychol. 2020;14(1):28-34. doi:10.1590/1980-57642020dn14-010005

28. Arvanitakis Z, Shah RC, Bennett DA. Diagnosis and management of dementia: review. JAMA. 2019;322(16):1589-99. doi:10.1001/jama.2019.4782

29. Silva HS, Gutierrez BAO. Care complexity in hospitalized elderly according to cognitive performance. Rev Bras Enferm. 2019;72(2):134-9. doi: 10.1590/0034-7167-2018-0357

30. Fransen NL, Holz M, Pereira A, Fonseca RP, Kochhann R. Accuracy of functional performance in healthy elderly subjects, with mild cognitive impairment and Alzheimer's Disease. Trends Psychol. 2018;26(4):1907-19. doi: 10.9788/tp2018.4-08pt

31. Parrish E. Delirium superimposed on dementia. Nurs Clin North Am. 2019;54(4):541-50. doi: 10.1016/j.cnur.2019.07.004

32. Ratford J. Confused about confusion? Lakeway: National Center of Continuing Education; 2012. 18 p.

33. Hugo J, Ganguli M. Dementia and cognitive impairment: epidemiology, diagnosis, and treatment. Clin Geriatr Med. 2014;30(3):421-42. doi: 10.1016/j.cger.2014.04.001

34. Prado CE, Watt S, Treeby MS, Crowe SF. Performance on neuropsychological assessment and progression to dementia: a meta-analysis. Psychol Aging. 2019;34(7):954-77. doi: 10.1037/pag0000410

35. Herdman TH, Kamitsuru S, editors. NANDA International Nursing Diagnosis: Definitions \& Classification, $2018-2020$ (11th ed.). New York, NY: Thieme Publishers; 2018. 473 p. 